\title{
Obstacles and Improvement Strategies in Implementing Flipped Classroom in Colleges: From the Perspective of Self-Determination Theory
}

\author{
Xiaoping Mai, Lihong Liu \\ School of Foreign Studies, Lingnan Normal University, Zhanjiang, China \\ Email: pearlmai@126.com,1125323123@qq.com
}

How to cite this paper: Mai, X. P., \& Liu, L. H. (2021). Obstacles and Improvement Strategies in Implementing Flipped Classroom in Colleges: From the Perspective of Self-Determination Theory. Advances in Applied Sociology, 11, 513-521.

https://doi.org/10.4236/aasoci.2021.1110045

Received: September 24, 2021

Accepted: October 25, 2021

Published: October 28, 2021

Copyright $\odot 2021$ by author(s) and Scientific Research Publishing Inc. This work is licensed under the Creative Commons Attribution International License (CC BY 4.0).

http://creativecommons.org/licenses/by/4.0/

\begin{abstract}
The stimulation of students' intrinsic motivation is an important factor in promoting the success of flipped classrooms. According to the theory of self-determination, colleges and teachers should break through the constraints of the social environment and start from the three dimensions of the technical environment, teacher teaching, and student learning to improve the quality of flipped classroom teaching. By constructing a technological environment which is conducive to students' autonomous learning, carefully producing and designing micro-class videos, and establishing a supportive and harmonious teacher-student relationship, the basic psychological needs of students can be met, and the efficiency and effectiveness of flipped classrooms can be improved.
\end{abstract}

\section{Keywords}

College Flipped Classroom, Self-Determination Theory, Obstacle, Strategy

\section{Introduction}

The development of information technology has promoted continuous innovation in the field of education. At the beginning of the 21st century, the flipped classroom model, which originated in the field of basic education in the United States, has received more and more attention from teachers, schools, and researchers since it was introduced to the world by the Khan Academy. At present, the flipped classroom researches have achieved some important results. Generally speaking, people hold a positive attitude towards flipped classrooms. In view of the potential advantages, the effectiveness of the flipped classroom model for the teaching 
and learning process, has been investigated by a significant body of research, across different subject domains and educational levels (Schultz, Duffield, Rasmussen, \& Wageman, 2014; Lo \& Hew, 2017; Stylianos, Demetrios, \& Lina, 2018; Khayat, Hafezi, Asgari, \& Shoushtari, 2020). However, some scholars have questioned the applicability and effects of flipped classrooms, thinking that students do not have good self-study habits, and the effect of pre-class work cannot be guaranteed (Hu, Cai, \& Zhang, 2019), teachers and students rely too much on technical means (Chen et al., 2016), and some researchers even considered it to be a kind of "disruptive innovation" model (Li, 2014). Some teaching practices at home and abroad have also confirmed that flipped classrooms have not effectively improved students' learning effects (Strayer, 2012; Yin, 2016).

Supported by information technology, the flipped classroom breaks the process of the traditional teaching model and reorganizes the learning time in and out of class. The learning activities are transformed from "teacher-centered" to "studentcentered", focusing on the main role of students in the learning process and reflecting the personalized learning style. In order to boost student engagement and help them to learn more effectively, improving students' motivation to participate in flipped classroom learning is an urgent problem that needs to be overcome (Miao \& Wang, 2015). However, there are relatively few studies on how the flipped classroom model affects students' learning satisfaction and internal needs throughout the learning process. In this context, this article will adopt Self-Determination Theory (SDT), a theory of human motivation and personality, as the main theoretical framework in order to understand the internal needs of students in the learning process, to analyze the obstacles to the implementation of flipped classrooms, and to put forward suggestions to improve the flipped classroom in colleges.

\section{Self-Determination Theory}

Self-determination theory is a learning motivation theory proposed by American psychologists (Deci \& Ryan, 1985). The theory assumes that people have a tendency to learn actively and constantly improve themselves, and it can be realized through interaction with the external environment. Through experiments, researchers have concluded three basic psychological needs: Autonomy, Competence, and Relatedness. In this theory, the need for autonomy is the need for self-determination, and the satisfaction of this need is the most important. When an individual feels a high degree of self-determination in an activity, he experiences an internal attribution and feels that he can dominate his activity. At this time, his internal motivation to participate in this activity is very high. Competence need refers to the individual's belief that his learning behavior or actions can reach a certain level, and that he can be competent for the activity. The need for relatedness means that the individual needs care, understanding, and support from the surrounding environment or other people to experience a sense of belonging. When various factors in the external environment meet the individual's ba- 
sic psychological needs, the individual will form a healthy psychology and positive behavior; otherwise, it will hinder the individual's development, and the individual will have a negative psychology and behavior.

Flipped classroom provides a student-centered exploratory learning environment. Students are not passive recipients of learning, but active builders of knowledge. Before class, students can independently adjust the learning time, learning content and learning progress according to their own preferences, and can also watch the video learning content repeatedly according to their own understanding. At the same time, students can raise their own questions and ideas while watching the video, communicate with teachers or peers, and complete the construction of knowledge independently. (Pass \& Wayne, 2014) research shows that if students can choose their own learning time and learning method to complete the task, they will have a sense of autonomy. In addition, in the flipped classroom teaching model, teachers answer questions and assist students in completing their homework in the classroom. Providing necessary help and guidance to students in the stage of internalization of knowledge helps to improve students' sense of competence in learning. (Abeysekera \& Dawson, 2015) pointed out that when students actively construct their knowledge, the sense of competence is the strongest. In terms of the sense of relatedness, the multi-level interaction between teachers and students in the flipped classroom helps to improve the intimacy between teachers and students and is conducive to fostering a sense of collective belonging among students.

\section{Research Method}

\subsection{Research Questions}

Motivated by the SDT perspective and based on previous research, the present study aimed to investigate how the flipped classroom teaching model affected students' learning satisfaction and students' internal needs in the learning process. The two research questions proposed were as follows:

1) Does the flipped classroom model help improve students' satisfaction of learning in the process of English learning?

2) Can the flipped classroom model meet the psychological needs of students during college English learning, that is, the needs of autonomy, competence and relatedness?

\subsection{Instrument and Data Analysis}

All participants were first-year students at a normal university in Zhanjiang City, Guangdong Province. The method of classroom observation was carried out to understand the performance of students in face-to-face classroom. At the same time, the above two research questions were further explored during semistructured interviews, in which twenty students were asked to talk about how the flipped classroom affected their psychological needs. As for the qualitative interview data, all of them were transcribed first and a qualitative inductive approach 
was adopted in data analysis (Strauss \& Corbin, 1998). In the process of data analysis, three meetings were held between the two authors to discuss the emerging themes and categories to reach a consensus on the final interpretation of the data.

\section{Findings and Discussion}

\subsection{Obstacles to Enhance Students' Self-Management and Improvement Strategies}

The need for student autonomy refers to the need for self-management by students. (Gagne \& Deci, 2005) proposed a theoretical model that affects autonomy. They believe that environmental factors and individual differences will affect autonomy. If the external environment of the students allows them to make free choices according to their own wishes, the students can effectively integrate the external rules. (Wang \& Pang, 2009) further pointed out that teachers should allow students to choose the time to complete homework, correct learning errors, set learning goals, and control learning time by themselves, so that students can experience the sense of responsibility for learning, thereby enhancing students' learning autonomy.

However, it is not easy for students to use their spare time for autonomous learning. First of all, the implementation of flipped classrooms increases the learning load of students. Compared with traditional teaching, students need to study the course content independently before class, such as watching videos, completing corresponding exercises and tests for discussion and comment in classroom teaching. Generally speaking, the time that students spend on the entire course is more than twice that of traditional classroom teaching. Therefore, some students do not like autonomous learning and are more willing to accept traditional teaching methods. Secondly, the learning effect of micro-classes in the self-study stage is not very satisfactory. Six of the interviewees said that the micro-classes were mostly fragmentary courses, and some were even tedious and lengthy, which reduced their autonomy in learning. According to (Chen et al., 2016), fragmented learning is not conducive to the deep learning of students, and the systematic teaching of teachers in the classroom not only ensures the integrity of the knowledge system, but also improves students' learning enthusiasm.

Extracurricular learning is an important part of the implementation of flipped classrooms. In order to improve the efficiency and autonomy of students' independent learning, it makes sense to start small, building students' confidence with flipped tasks that let them practice and learn without becoming overwhelmed. As for the quality of the micro-class videos, it is best for the school to establish a dedicated video recording studio with a professional production team, or cooperate with professional production companies and publishing companies outside the school to record videos. Of course, some courses can use high-quality public videos, but more need to use the micro-classes designed and produced by teachers themselves. At the same time, the application of social media can effec- 
tively cooperate with flipped classroom teaching. Teachers can make use of college students' love and communication habits of WeChat and QQ to establish a WeChat group or QQ group for course learning to facilitate instant interaction between teachers and students. The convenience and timely feedback functions of WeChat and QQ groups can enhance students' initiative and enthusiasm in learning.

\subsection{Obstacles to Improve Students' Competence and Improvement Strategies}

In flipped classrooms, the micro-videos for students to learn independently has become an indispensable part, which requires deep intervention of information technology to realize the visualization of teaching information such as text, images, photos, animation, data, etc. However, the composition of digital works used in flipped classroom teaching is quite complex. Undisclosed original works and publicly published publications all involve the protection of intellectual property rights. Teachers are generally very cautious when using public videos and references. Due to intellectual property issues, some public videos, books, and essays can only be displayed as fragments or partial excerpts, which will affect students' understanding of the course content and hinder the improvement of their competence. The results of an empirical study show that a good teaching video helps students complete learning tasks efficiently. Compared with non-interactive video, video-free online teaching, and traditional classroom teaching, interactive online video has better teaching effects, and students' learning satisfaction is higher (Zhang et al., 2006). Although the quality of the video recorded by the professional team is obviously better than the teacher's self-made video, due to the limitation of funds, many teachers use self-made video for pre-class in teaching. Some teachers even simply record PPT without appearing on the camera, causing students to spend a lot of time watching videos, but they have not improved their learning ability. One of the interviewees in this study stated "I don't know what I need to do tomorrow in class. The content in the micro-video is not relevant and specific to the course. I feel so confused". This comment indicated that the videos were not well planned and structured by the teacher, which was not conducive for students to achieve their goals and develop competence.

In order to improve the quality of micro-videos, it is important for teachers to create the videos rather than simply curate them from other sources. The proper selection, design and explanation of the knowledge points in the video are the key to success. According to related research, in order to meet the needs of students' fragmented learning, the time of each video should be controlled within 8 - 15 minutes, and test questions should be embedded in the video ( $\mathrm{Li}, 2013$ ). Therefore, teachers should first decompose the knowledge points of the entire course, select the key and difficult points for design, and must explain one or two knowledge points thoroughly within a limited time, and ensure that students can understand and absorb. Some scholars suggest that enterprises and institutions should undertake the design and production of video resources, and teachers 
only make a small number of videos based on the actual teaching as a supplement (Fang, 2014). In this regard, the author holds different opinions, because even for the same course, different teachers have different understanding and design of the course, and students come from different majors and levels, so naturally there are differences in the degree of acceptance of knowledge. Therefore, the instructor must personally design a video suitable for himself and his students, and meticulously design various forms of exercises to match the video.

\subsection{Obstacles to Meet Students' Relatedness Needs and Improvement Strategies}

The need for relatedness means that students can get support and help from teachers and classmates in their studies, and have the need to be valued and connect with others. (Zhou et al., 2009) analysis of a questionnaire survey on primary school students in rural areas of China confirmed that teachers' autonomous support positively predicts students' autonomous motivation and perception abilities. In flipped classroom learning, in addition to the support of the teacher, peer relationship is also very important for learning support inside and outside the classroom. Peer relationship refers to a kind of interpersonal relationship established and developed in the process of mutual communication between peers or individuals with the same level of psychological development, and plays a unique role in the development of adolescents. Peer relationship is an important source of meeting the relationship needs of college students and obtaining social support and a sense of security (Zou, 1998).

However, in the implementation of flipped classrooms, there are significant obstacles to teachers' autonomous support and the construction of students' peer relationships. Generally, the teaching objects of flipped classrooms in colleges come from different departments and majors. In the temporary teaching classes, most students do not know and are familiar with each other in advance. In order to complete the required credits, a student needs to participate in different courses taught by different teachers. Therefore, for teachers, it is a creative and challenging task to teach students of different majors and provide learning support for these students. At the same time, it is also a challenging task for students who register for different courses and adapt to different teachers and peers.

The success of the flipped classroom depends on the support of the technical environment and the meticulous design of the instructors on the one hand, and the independent learning ability of the students on the other hand. (Qu \& Miao, 2021) pointed out that in flipped classroom, students' learning strategies are passive and not rich. Therefore, in order to take advantages of flipped classroom better, supervision and guiding role of teachers should be strengthened. Teachers can provide online guidance on students' autonomous learning outside of class, and they can also have face-to-face communication with students in class. Multi-level interaction between teachers and students helps to increase the intimacy between teachers and students. Students can also cooperate with each other through group activities. Group members form a learning community and work together 
to complete tasks, which help to foster a sense of collective belonging among students.

Solving the problems encountered before class through individual self-study and group discussion is one of the most challenging aspects of flipped classrooms. For teachers, pre-class learning is just a warm-up process. Teachers should introduce students into preset learning scenarios, so that students can master the knowledge they have learned by personally participating in group debates and classroom discussions, and interacting with teachers and classmates. Teachers not only need to pay attention to group discussions and homework presentations in the classroom, but also to put forward expansive and in-depth questions in a timely manner to further stimulate students' learning initiative and creativity.

\section{Conclusion}

This study attempts to use self-determination theory to analyze the obstacles to the implementation of flipped classrooms, and put forward suggestions for perfecting flipped classrooms in colleges and universities. Stimulating students' learning motivation is a prerequisite for improving learning efficiency. In order to improve the teaching effect of flipped classrooms, schools and teachers must create a student-centered learning environment, carefully produce and design micro-class videos, and build a new type of teacher-student relationship, so as to further enhance students' sense of autonomy, competence and relatedness in learning. The time and attention spent on facilitating students' learning will pay off in flipped classroom teaching.

\section{Acknowledgements}

This paper and the study are funded by: Fund Project 1: College English teaching reform project of Guangdong province "Research and Practice of College Academic English Teaching Model Based on Functional Language Analysis" (Project No.: YDY-2019-19); Fund Project 2: Research and Practice on the Classroom Teaching Reform of College English Extended Course Group Based on PAD Class Mode.

\section{Conflicts of Interest}

The authors declare no conflicts of interest regarding the publication of this paper.

\section{References}

Abeysekera, L., \& Dawson, P. (2015). Motivation and Cognitive Load in the Flipped Classroom: Definition, Rational and a Call for Research. Higher Education Research \& Development, 34, 1-14. https://doi.org/10.1080/07294360.2014.934336

Chen, Y., Hu, F. G., Liu, Y. Q., \& Liu, J. L. (2016). Thinking about the Contradictory Relationship Caused by Flipped Classroom. Modern Educational Technology, 26, 71-76. 
Deci, E. L., \& Ryan, R. M. (1985). Intrinsic Motivation and Self-Determination in Human Behavior. Springer. https://doi.org/10.1007/978-1-4899-2271-7

Fang, Y. Y. (2014). Research on the Online Support Environment of Flipped ClassroomTaking Khan Academy Online Platform as an Example. Journal of Distance Education, $6,41-48$.

Gagne, M., \& Deci, W. L. (2005). Self-Determination Theory and Work Motivation. Journal of Organizational Behavior, 26, 331-362. https://doi.org/10.1002/job.322

Hu, F., Cai, X., \& Zhang, X. (2019). A Flipped Classroom Designed for the Teaching of "Network Equipment Configuration and Management". Open Journal of Social Sciences, 7, 201-208. https://doi.org/10.4236/jss.2019.75016

Khayat, M., Hafezi, F., Asgari, P., \& Shoushtari, M. T. (2020). Comparing the Effectiveness of Flipped and Traditional Teaching Methods in Problem-Solving Learning and Self-Determination among University Students. Journal of Medical Education, 19, Article ID: e110069. https://doi.org/10.5812/jme.110069

Li, M. L. (2013). The Characteristics of MOOCs and the Principles of Instructional Design. Educational Research of Tsinghua University, 34, 13-21.

Li, Y. (2014). Rational Thinking on China's Craze for Flipped Classrooms. Teaching Material and Teaching Method, 34, 18-23.

Lo, C. K., \& Hew, K. F. (2017). A Critical Review of Flipped Classroom Challenges in K-12 Education: Possible Solutions and Recommendations for Future Research. Research and Practice in Technology Enhanced Learning, 12, Article No. 4. https://doi.org/10.1186/s41039-016-0044-2

Miao, J. M., \& Wang, Q. (2015). Flipped Classroom in Colleges and Universities: Status Quo, Effectiveness and Challenges-Based on a Survey of Practical Frontline Teachers. Open Education Research, 21, 74-82.

Pass, M., \& Wayne, A. N. (2014). Student Effort: The Influence of Relatedness, Competence and Autonomy. Academy of Educational Leadership Journal, 18, 1-12.

Qu, X. M., \& Miao, R. (2021). Research of Learning Strategies in Flipped Classroom. Open Access Library Journal, 8, 1-8.

Schultz, D., Duffield, S., Rasmussen, S. C., \& Wageman, J. (2014). Effects of the Flipped Classroom Model on Student Performance for Advanced Placement High School Chemistry Students. Journal of Chemical Education, 91, 1334-1339.

https://doi.org/10.1021/ed400868x

Strauss, A., \& Corbin, J. (1998). Basics of Qualitative Research. Sage.

Strayer, J. (2012). How Learning in an Inverted Classroom Influences Cooperation, Innovation and Task Orientation. Learning Environments Research, 15, 171-193. https://doi.org/10.1007/s10984-012-9108-4

Stylianos, S., Demetrios, G. S., \& Lina, P. (2018). Investigating the Impact of Flipped Classroom on Students' Learning Experiences: A Self-Determination Theory Approach. Computers in Human Behavior, 78, 368-378. https://doi.org/10.1016/j.chb.2017.08.011

Wang, T. T., \& Pang, W. G. (2009). The Enlightenment of Self-Determination Theory on the Cultivation of Students' Autonomous Learning Ability. Global Education Outlook, $38,40-43$.

Yin, H. D. (2016). Calm Thinking on the Craze for Flipped Classrooms at Home and Abroad: Empirical Evidence and Reflection. National Education Research, 27, 25-30.

Zhang, D., Zhou, L., Briggs, R. O., \& Nunamaker, J. F. (2006). Instructional Video in E-Learning: Assessing the Impact of Interactive Video on Learning Effectiveness. Information 
\& Management, 43, 15-27. https://doi.org/10.1016/j.im.2005.01.004

Zhou, M., Ma, W. J., \& Deci, E. L. (2009). The Importance of Autonomy for Rural Chinese Children's Motivation for Learning. Learning and Individual Differences, 19, 492-498. https://doi.org/10.1016/j.lindif.2009.05.003

Zou, H. (1998). The Developmental Function and Influencing Factors of Peer Relationship. Psychological Development and Education, 2, 39-44. 